\title{
Erratum
}

Psychopharmacology (1994) 115:320-324

\section{Caffeine augmentation of electroconvulsive seizures}

\author{
Andrew Francis, Laura Fochtmann
}

Department of Psychiatry and Behavioral Sciences, SUNY Stony Brook, Stony Brook, NY 11794, USA

Received: 28 September 1993 / Final version: 8 December 1993

On pages 321 and 322 of this paper, Figs. 1 and 3 were unfortunately interchanged. Figures 1 and 3 are reprinted below together with the correct legends.

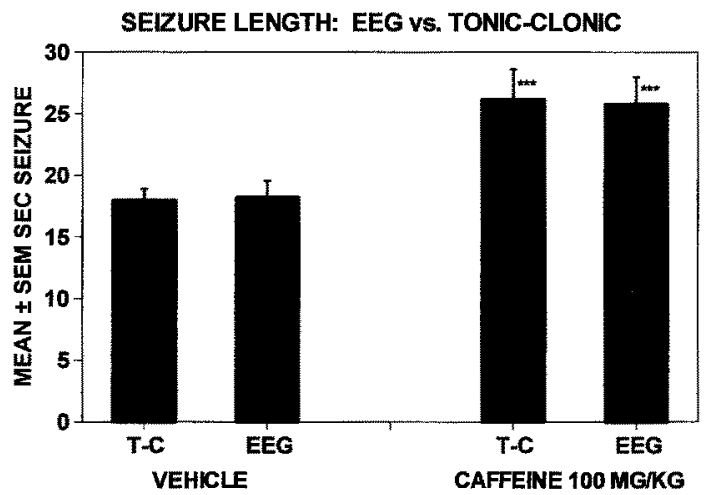

Fig. 1. Correspondence of behavioral estimates of seizure duration by length of tonic-clonic convulsions $(T-C)$ and EEG determined seizure length. There was a significant increase in seizure length by caffeine $(F=18.3, d f=1, * * * P<0.002)$ but no difference between behavioral and EEG measures of seizure length $(F<1, d f=1$, $P>0.9)$
TIME COURSE OF CAFFEINE AUGMENTED ECS

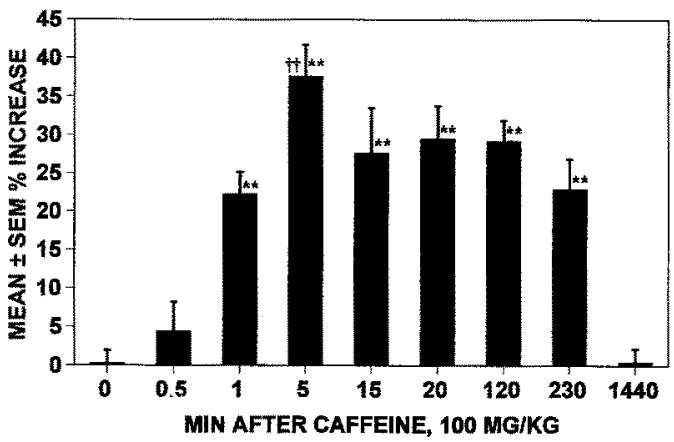

Fig. 3. Time course for caffeine augmentation of ECS at various intervals after a fixed dose of $100 \mathrm{mg} / \mathrm{kg}$. The duration of tonicclonic convulsions $(T-C)$ is expressed as percent increase over vehicle injection at $0 \mathrm{~min}$. A significant increase was detectable at $1 \mathrm{~min}$ (Tukey- $t=6.54,{ }^{* *} P<0.01$ ) and at all intervals afterward except for $1440 \mathrm{~min}$. Seizure duration at $5 \mathrm{~min}$ was greater than that at $1 \mathrm{~min}$ (Tukey $t=3.40,{ }^{\dagger+} P<0.10$ ) and at $230 \mathrm{~min}$ (Tukey $t=2.66$, $\left.{ }^{+} P<0.01\right)$ but not different at intervening periods. The seizure duration at $1440 \mathrm{~min}$ was not different from control. 